\title{
Trabalho e aposentadoria militar: singularidades de uma travessia psíquica
}

\author{
Paula Kegler - Pontificia Universidade Católica do Rio Grande do Sul, Porto Alegre, Brasil \\ Faculdades Integradas de Taquara, Taquara, Brasil \\ Mônica Medeiros Kother Macedo - Pontifícia Universidade Católica do Rio Grande do Sul, Porto Alegre, Brasil
}

\begin{abstract}
Resumo
O caráter central do trabalho remete à lógica capitalista, na qual a atividade profissional é um requisito para a participação nos processos sociais e produtivos. Um rompimento com a profissão decorrente da aposentadoria configura-se como uma vivência de grande impacto psíquico. Este estudo teve como objetivo investigar, a partir de uma metodologia qualitativa, as especificidades do trabalho e da aposentadoria militar. Foram realizadas entrevistas com 13 militares aposentados. A categorização dos dados foi realizada por meio da análise de conteúdo, e a interpretação dos dados teve o embasamento na Psicanálise. Constatou-se que a vida militar e seu exercício de trabalho configuram um processo identificatório com peculiaridades. Percebeu-se a necessidade de trabalho psíquico diante da aposentadoria, seja para atribuir sentido ao vivido ou para compensar frustrações advindas dessa situação. A escuta, na pesquisa, revelou-se um recurso de fomento à elaboração frente a intensidades despertadas na retirada do sujeito da vida laborativa.
\end{abstract}

Palavras-chave: trabalho; aposentadoria; psicologia militar; psicanálise.

Labour and military retirement: singularities of a psychic journey

\begin{abstract}
The main aspect of the work refers to the capitalist logics in which the professional activity is required in social and productive processes. When someone retires, there is a rupture with a professional activity that generates in this person a great psychic impact. This study aimed to investigate, from a qualitative methodology, the specificities of work and retirement in the military context. Thirteen retired militaries were interviewed. The categorization of data was done through Analysis of Content and interpretation of data was the basement of Psychoanalysis. As a result, military life and work are related to subjects' identification process. The necessity of a psychicological effort was observed through retirement experiences whether it is used to give meaning or to compensate frustrations from these situations. The listening in research was demonstrated as a resource to psychicological work over the intensities revealed upon the retirement.

Keywords: labour; retirement; military psychology; psychoanalysis.
\end{abstract}

Trabajo y jubilación militar: singularidades de una travesía psíquica

\section{Resumen}

El rol central del trabajo remite a la lógica capitalista, en la cual la actividad profesional es un requisito para la participación en los procesos sociales y productivos. La ruptura con la profesión, cuando los individuos se jubilan, aparece como una experiencia de gran impacto psicológico. El propósito de este estudio fue investigar a través de un método cualitativo, las especificaciones del trabajo y de la jubilación militar. Se realizaron entrevistas con 13 militares jubilados. La categorización de los datos se realizó mediante el Análisis de Contenido y su interpretación tuvo como base el Psicoanálisis. Se constató que la vida militar y su ejercicio de trabajo configuran un proceso de identificación con particularidades. Se observó la necesidad de trabajo psíquico frente a la etapa de jubilación, ya sea para darle significado a la experiencia vivida o para compensar frustraciones derivadas de la misma. El resultado de esta investigación resultó ser un recurso de elaboración frente a la intensidad emocional que despierta la salida de la vida laboral.

Palabras-clave: trabajo; jubilación; psicología militar; psicoanálisis.

\section{Introdução}

O caráter central do trabalho para o sujeito está inserido na lógica capitalista dos tempos atuais, na qual a atividade profissional está incluída nos requisitos para a participação humana nos processos produtivos da sociedade. O afastamento do mundo do trabalho decorrente da aposentadoria vem acompanhado de alterações na rotina diária e no vínculo com o sistema social. Santos (1990) afirma que o trabalho dá ao homem um papel social na medida em que suas características

Disponivel em www.scielo.br "penetram na personalidade do sujeito, tornando-se parte de sua identidade" (p. 2). Nessa perspectiva, ao considerar o trabalho como um elemento constitutivo do ser humano, Enriquez (1999) nomeia qualquer tipo de perda de trabalho como uma ferida identitária.

A complexidade da vida laborativa articula-se ao modelo freudiano da teoria do apoio. Em Três ensaios sobre a teoria da sexualidade, Freud (1905/1996) apresenta a proposição de que a irrupção da sexualidade se dá a partir de demandas dos instintos de sobrevivência: a pulsão nasce apoiada nas demandas de 
autoconservação. Nesse sentido, por meio da busca de reprodução da vivência prazerosa, que instaura o desejo sexual, surge a especificidade da realidade psíquica e os rumos singulares das vicissitudes pulsionais do sujeito. A motivação e o exercício de uma atividade laboral também se inscreverão nesse complexo campo da satisfação pulsional. Pode-se reconhecer, assim, que a finalidade primeira da atividade do trabalho é sustentada por uma conduta humana que tem o objetivo de atender demandas autoconservativas, porém o prazer e o sentido a ela atribuídos extrapolam o campo autoconservativo. Logo, apoiada nessa necessidade básica de manter o próprio sustento, a vivência laboral vai além das demandas instintuais. Passa a ser por meio do trabalho que o sujeito tece e articula, no cenário de sua vida psíquica, as possibilidades de promover singulares experiências de ordem pulsional. Trata-se, portanto, de reconhecer o investimento libidinal que permeia toda escolha e atividade de trabalho humano.

Em O mal-estar na civilização, Freud (1930/1996) situa o trabalho como um caminho potencial na busca do prazer, ao mesmo tempo em que permite uma nova forma de articulação com a realidade. $\mathrm{O}$ autor nomeia o trabalho como um veículo da coesão social na medida em que favorece a manutenção de laços com o semelhante e o nascimento da civilização. $O$ trabalho pode ser considerado, então, como "um elemento fundamentalmente integrador da sociedade, isto é, permite efetivamente a uma sociedade engendrar ou reforçar os laços sociais" (Enriquez, 1999, p. 72). De acordo com Coutinho, Krawulski e Soares (2007), o contato com as pessoas no ambiente de trabalho compõe a principal ferramenta de sociabilidade do homem.

No contexto da atividade laboral, também pode integrar-se a experiência de aposentadoria. Os sentidos que esse termo evoca são compreendidos por Carlos, Jacques, Larratea e Heredia (1999), com duas acepções centrais. A primeira refere-se ao vocábulo "jubilamento", como júbilo, conquista e recompensa. A segunda propõe a concepção da aposentadoria como um recolhimento aos aposentos, ou seja, a retirada da vida ativa para o interior do espaço doméstico. Costa e Soares (2009) afirmam que o término da vida laboral corresponde a uma visão de homem sem importância social. As autoras definem que o ato de aposentar-se, engendrado nas propriedades de uma cultura capitalista, "tende a ser acompanhado por valores negativos como inutilidade, incapacidade e envelhecimento. Por conseguinte, o aposentado é quem não possui mais utilidade para a manutenção do sistema produtivo" (p.102).
Nessa perspectiva, compreende-se a aposentadoria como uma experiência de crise, nomeada por Santos (1990) como aposentadoria-recusa. A problematização da aposentadoria como recusa encontra ressonância na teorização freudiana sobre a negação. Considerado um mecanismo psíquico que indica um sinal da manifestação de conteúdos inconscientes, que somente têm acesso à consciência quando negados, revela a presença de conflitos que se expressam em forma de negativa porque $\mathrm{o}$ sujeito não pode admiti-los (Freud, 1925/1996). Nesse sentido, em um estudo sobre as representações sociais da aposentadoria, Graeff (2002) demonstra a ambivalência vinculada ao afastamento do trabalho, podendo a aposentadoria ser caracterizada como uma perda ou como um recomeço. No entanto, mesmo com acepções ambivalentes, a maneira particular pela qual cada um realiza o trabalho psíquico necessário para dar conta desses investimentos naturalmente direcionados à vida laboral associa-se às relações de trabalho estabelecidas ao longo da vida.

Os sentidos atribuídos ao trabalho, bem como o impacto subjetivo do rompimento com o papel profissional foram investigados em variadas classes trabalhistas (Graeff, 2002; Morin, Tonelli, \& Pliopas, 2007; Santos, 1990). O interesse por explorar essa temática no âmbito militar surgiu em função das especificidades da construção das relações de trabalho nesse contexto. Segundo Barisch (2006), o exercício do militarismo impõe o comprometimento da própria vida a serviço da pátria e para o bem da nação. Para o autor, a própria nomeação da aposentadoria militar carrega uma série de significados: o ato de aposentar-se é denominado passagem para a reserva. $\mathrm{Na}$ reserva, por sua vez, os militares passam a ser chamados de inativos. Neste estudo, exploram-se as singularidades do serviço militar a fim de compreender a maneira como a passagem para a reserva se diferencia da aposentadoria em outras atividades profissionais. $\mathrm{Na}$ vida militar, a saída da ativa se dá por tempo de serviço prestado (no mínimo 30 anos $^{1}$ ) e em função do posto ocupado pelo militar, o que interfere diretamente na forma como esses sujeitos encaram a inatividade. Buscou-se, por meio de entrevistas com militares do sexo masculino, acessar os significados atribuídos ao serviço ativo e à experiência de passagem para a reserva. Logo, constitui-se como objetivo deste estudo investigar, a partir dos pressupostos teóricos da

\footnotetext{
${ }^{1} \mathrm{Na}$ contagem do tempo de serviço para os militares podem ser computados outros acréscimos além dos anos de efetivo serviço, levando em consideração averbações de períodos trabalhados anteriormente ao ingresso na carreira militar.
} 
Psicanálise, as singularidades da experiência do trabalho e da aposentadoria nesse contexto.

\section{Método}

Numa tentativa de alcançar as significações particulares atribuídas pelos sujeitos ao fenômeno em estudo e seus efeitos na subjetividade, optou-se pela realização de uma pesquisa qualitativa exploratória.

\section{Participantes}

A coleta dos dados foi realizada em uma organização militar da Força Aérea Brasileira. Foram levantadas informações referentes a 213 militares, por estarem em conformidade com os seguintes critérios de inclusão: serem do sexo masculino e terem se aposentado por tempo de serviço no período entre janeiro de 2006 e dezembro de 2008. A partir dessas informações iniciais, elegeram-se, por conveniência, 13 participantes para serem entrevistados, de modo a contemplar o acesso à maior parte possível dos cargos pertencentes à hierarquia militar. Assim, foram escolhidos, deliberadamente, no mínimo, três participantes de cada posto ou graduação.

Os seguintes índices retratam a caracterização dos dados pesquisados: do grupo total, composto por 213 sujeitos, $21,6 \%$ eram oficiais (cargos de chefia e liderança) e 78,4\% graduados (encarregados de executar as determinações dos oficiais, exercendo atividades mais técnicas). Observa-se que a porcentagem de graduados que foram para a reserva no período abrangido pela coleta é expressivamente maior do que a de oficiais, o que reflete a realidade institucional. Em relação ao estado civil, 84\% mantém casamento ou união estável, $11 \%$ divorciados, $4 \%$ solteiros e $1 \%$ viúvos. Constata-se, portanto, a grande maioria dos militares constituiu família, mantendo-se casados ou em união estável, de modo que o número de solteiros é baixo.

A idade média de ingresso na reserva foi de 50,07 anos, sendo considerada baixa para os padrões da população brasileira. O tempo de serviço médio efetuado foi de 31,57 anos, o que significa que os militares ficaram na ativa por um tempo maior do que o mínimo previsto para a concessão da aposentadoria (30 anos). A parcela dos militares que optaram por retornar ao trabalho após a aposentadoria, processo denominado Tarefa por tempo certo, foi de $7 \%$, sendo que destes, $60 \%$ são oficiais e $40 \%$ são graduados.

No grupo dos oficiais, o período trabalhado se eleva à média de 33,6 anos e a idade média a 51,8 anos.
Verifica-se que, entre os sujeitos que voltaram a exercer suas atividades por um tempo determinado, a incidência também é maior entre os oficiais. Cabe ressaltar que isso se deve ao fato de o oficial ocupar uma posição de chefia, com melhor remuneração, maior grau de instrução e responsabilidades, sendo mais respeitado e reconhecido na hierarquia, o que torna o seu trabalho mais atrativo.

Os dados sociodemográficos dos 13 militares participantes da pesquisa estão explicitados na Tabela 1. Foram entrevistados seis oficiais (três coronéis e três capitães) e sete graduados (três suboficiais e quatro sargentos). Nenhum dos militares entrevistados voltou ao trabalho ativo na modalidade de Tarefa por tempo certo.

\section{Instrumentos}

Como instrumento de investigação, realizou-se, com cada participante, uma entrevista semiestruturada, contendo questões abertas, composta pelos seguintes eixos temáticos: (1) visão do participante sobre o papel social, econômico e psíquico desempenhado pelo trabalho na vida do homem; (2) significados atribuídos pelo participante ao trabalho e à aposentadoria, de forma mais geral; (3) significados atribuídos à sua experiência profissional; (4) forma como o participante vivenciou o processo de sua aposentadoria; (5) sentimentos advindos desse rompimento com o mundo do trabalho e (6) aspectos que o participante considera como facilitadores e/ou restritivos da vivência da aposentadoria.

\section{Procedimentos de coleta dos dados}

Os procedimentos para coleta dos dados envolveram, inicialmente, uma consulta a documentos disponíveis em um setor específico da instituição responsável pelo arquivo dos dados referentes ao pessoal inativo (militares aposentados). Após aprovação do projeto de pesquisa pelo Comitê de Ética em Pesquisa da Universidade, foi enviada uma carta à residência dos sujeitos que atendiam aos critérios de inclusão, explicando os objetivos da pesquisa e os convidando a participar do processo. Mediante contato telefônico com os militares, procedeu-se à marcação da entrevista. Apenas um, dos 13 possíveis participantes, não aceitou fazer parte da pesquisa alegando alto envolvimento com o trabalho. As entrevistas foram gravadas em áudio, após a devida autorização do participante, mediante a assinatura de um Termo de Consentimento Livre e Esclarecido. O encerramento da coleta dos 
Tabela 1. Dados Sociodemográficos dos Participantes

\begin{tabular}{lcccc}
\hline Participante & Idade & Est. civil & Posto/ graduação $^{*}$ & Tempo de serviço \\
\hline 1 & 49 anos & casado & sargento & 31 anos \\
2 & 54 anos & casado & capitão & 34 anos \\
3 & 49 anos & casado & capitão & 39 anos \\
4 & 52 anos & casado & coronel & 37 anos \\
5 & 50 anos & união estável & suboficial & 32 anos \\
6 & 46 anos & divorciado & suboficial & 30 anos \\
7 & 49 anos & casado & suboficial & 31 anos \\
8 & 48 anos & casado & sargento & 31 anos \\
9 & 49 anos & divorciado & coronel & 30 anos \\
10 & 48 anos & casado & sargento & 30 anos \\
11 & 48 anos & casado & coronel & 33 anos \\
12 & 49 anos & solteiro & capitão & 34 anos \\
13 & 49 anos & divorciado & sargento & 32 anos \\
\hline
\end{tabular}

*A hierarquia militar da Aeronáutica corresponde à seguinte ordem crescente: soldado, cabo, sargento, suboficial, tenente, capitão, major, tenente-coronel, coronel e brigadeiro.

dados deu-se no momento em que o conteúdo das informações tornou-se repetitivo, sendo improvável a construção de novas compreensões a respeito do fenômeno, de acordo com o critério de exaustão/saturação proposto por Bodgan e Biklen (1994).

\section{Procedimentos de análise dos dados}

Para a análise dos dados, foi realizado o desmembramento do texto transcrito das entrevistas em unidades e o posterior reagrupamento em categorias, de acordo com o método da Análise de conteúdo de Bardin (1991), a partir da releitura de Moraes (1999), a qual estabelece cinco etapas: preparação, unitarização, categorização, descrição e interpretação. Essa proposta de análise de dados em pesquisas qualitativas contempla um conjunto de técnicas sistematizadas utilizadas para a descrição e interpretação do conteúdo de uma mensagem com o propósito de alcançar um nível de entendimento mais aprofundado daquele que é proporcionado por uma simples leitura. Ao considerar que esta pesquisa valorizou a experiência humana em sua singularidade e em função de suas motivações inconscientes, optou-se por utilizar o embasamento teórico da Psicanálise para a interpretação dos dados resultantes da análise de conteúdo qualitativa.

\section{Resultados e Discussão}

O material decorrente da transcrição das entrevistas permitiu a identificação de unidades de significado, as quais foram codificadas e ordenadas em categorias iniciais. Estas, por sua vez, depois de agrupadas, formaram as categorias intermediárias que, por último, foram conjugadas em três categorias finais. A discussão de cada categoria final conta com a reprodução fiel de algumas verbalizações dos entrevistados, a fim de propiciar rigor e legitimidade às categorias. A primeira categoria final foi nomeada "O trabalho e a vida militar: singulares enlaces entre narcisismo e ideais" (Tabela 2).

Essa categoria sugere que estar trabalhando, no atual contexto cultural, figura dentre os principais objetivos da vida de um homem. Percebe-se, a partir da fala dos entrevistados, que o ato de trabalhar possibilita, não somente, o sustento financeiro, mas, também, a realização de conquistas pessoais:

"O trabalho me trouxe a satisfação financeira de ter dinheiro, de conseguir ter uma casa, um carro, de ter independência. Isso foi muito bom, fruto do meu trabalho também. De poder constituir uma família, de ter aquilo que é necessário." (P11, Coronel)

Psico-USF, Bragança Paulista, v. 20, n. 1, p. 25-38, jan./abr. 2015 
"Sou de uma família bumilde de cinco irmãos e meus pais não tinham condições de bancar uma faculdade, e ai começa a restringir a gama de opções para trabalhar. Então, en comecei a trabalhar por necessidade. Ai, depois en consegui fazer faculdade." (P3, Capitão)

Essas assertivas vão ao encontro dos achados da pesquisa realizada por Morin, Tonelli e Pliopas (2007) acerca dos sentidos atribuídos ao trabalho. $\mathrm{O}$ estudo dos autores constatou que a remuneração advinda do exercício laboral possibilita o alcance de outros projetos: aquisição de moradia, melhor qualidade de vida, melhores condições para criar os filhos, independência e amadurecimento. Para os entrevistados, a opção pela carreira militar por apreço e pela perspectiva de trabalhar com o que gosta podem potencializar uma experiência de satisfação no âmbito da vida laboral, como se observa no seguinte discurso:

"Sempre fui satisfeito com as minhas tarefas, sempre gostei do que eu fir. Sempre gostei da atividade militar. Gosto da hierarquia, gosto da disciplina, gosto do regime. Particularmente, eu me realizei na vida militar." (P4, Coronel)

Ao permitir que o sujeito faça parte de um grupo que o insere num contexto social e produtivo, a atividade profissional comporta, ainda, recursos que possibilitam a efetiva participação do sujeito na sociedade. Atributos como camaradagem e solidariedade são altamente promovidos e valorizados no ambiente de trabalho militar, onde acabam se produzindo trocas afetivas que podem ser consideradas pontos de apoio do sujeito no circuito social, como revela o entrevistado:

"O militar é bom porque é um grupo bastante unido. Quando toca a corneta, todo mundo tem que avançar. Sabe ao mesmo tempo que vai levar chumbo, mas tem que avançar. Avança todo mundo junto exatamente pela união, pela manutenção da amizade, até porque está previsto no regulamento. Essa parte ai sempre foi muito boa no quartel. $\mathrm{Na}$ bora de confraternização, todo mundo confraterniza, na hora de trabalhar, todo mundo trabalha junto. Tu consegue andar meio protegido, que isso dá uma certa proteção." (P2, Capitão)

O ingresso na vida militar é acompanhado da exigência de observância e obediência a regras disciplinares e preceitos hierárquicos que condicionam a vida pessoal e profissional do sujeito. Barisch (2006) descreve que o militarismo envolve uma dedicação total ao trabalho, pois obriga o militar a comprometer a própria vida "em atividades tipicamente bélicas, na

Psico-USF, Bragança Paulista, v. 20, n. 1, p. 25-38, jan./abr. 2015 defesa da pátria, na garantia dos poderes constitucionais e da lei e da ordem" (p. 24). O autor assinala que o efeito dessas imposições é percebido, principalmente, pelo impacto causado na vida familiar. As falas dos participantes ilustram essas considerações diante das exigências da profissão:

\begin{abstract}
"Tinha dias que eu chegava em casa, as minhas filhas e a minha esposa já estavam dormindo, e eu saía antes de elas acordarem. Eu tinha um contato restrito com elas. $A$ minha profissão era muito atribulada, eu viajava muito, não tinha tempo. Esses trinta anos foram dedicados à $\mathrm{FAB}$, eu quase não via a minha familia." (P7, Suboficial)
\end{abstract}

Essas particularidades são apontadas por Barisch (2006) como responsáveis pelo forte vínculo que o militar e a sua família mantêm com a instituição, ainda que existam conflitos entre as aspirações pessoais e os interesses institucionais. A atividade profissional, além de tomar uma parcela significativa do tempo na vida adulta, cumpre função de suporte de investimentos e de padrão identificatório. Morin et al. (2007) consideram que "a própria identidade das pessoas muitas vezes se confunde com seu trabalho" (p. 54). Assim, a vida laboral promove a identificação do sujeito com a profissão e com os valores da sua instituição:
"Ser militar é a coisa mais fácil que tem, é só tu ler as instruções. É só tu ler o manual, o que fazer e o que não fazer. É fácil, tu segue aquilo. Uma coisa que en sem- pre gostei é manter a disciplina, a roupa alinhada, corte de cabelo, barba. Sempre tento manter o padrão porque en gosto, me sinto bem. Deixar o cabelo crescer e a barba grande... eu não consigo me entender assim desleixado! Não sou eu assim, eu não me identifico assim." (P10, Sargento)

\begin{abstract}
"Enquanto a pessoa está no serviço, ela tem aquele envolvimento, aquele comprometimento, ela tem uma farda. Quer queira, quer não queira, ainda tem um nivel de respeito em qualquer lugar que se vá.” (P5, Suboficial)
\end{abstract}

Os relatos mostram que o regulamento deliberativo das condutas militares representa um modelo identificatório fundamental, assim como o próprio uniforme militar figura-se como um invólucro narcísico mediante o qual o sujeito se reconhece a partir de um valor social atribuído à sua condição. Tal identificação com a profissão militar, socialmente valorizada, está intimamente associada à autoestima. De acordo com Morin et al. (2007), o reconhecimento pelo trabalho dá sentido à atividade realizada, e legitima a identidade profissional. Para alguns militares entrevistados neste 
Tabela 2. Primeira Categoria Final

\begin{tabular}{lll}
\hline Categorias iniciais & $\begin{array}{l}\text { Categorias } \\
\text { intermediárias }\end{array}$ & $\begin{array}{l}\text { Primeira categoria } \\
\text { final }\end{array}$ \\
\hline Trabalho possibilitando satisfação pessoal. & $\begin{array}{l}\text { Trabalho como } \\
\text { alicerce de }\end{array}$ & $\begin{array}{l}\text { O trabalho e a vida } \\
\text { militar: singulares } \\
\text { Trabalho proporcionando melhores oportunidades na vida. }\end{array}$ \\
$\begin{array}{l}\text { Trabalho proporcios pessoais, } \\
\text { enlaces entre } \\
\text { Trabalho promovissionais e }\end{array}$ & narcisismo e ideais \\
sociais &
\end{tabular}

Trabalhar $=$ estar vivo.

Trabalho proporcionando crescimento profissional.

Trabalho oportunizando convívio com as pessoas e inserção social.

Opção por seguir carreira associada ao gosto pela vida militar.

Vida militar como opção para famílias humildes e com poucas condições de investir no estudo dos filhos.

Exigência de presença no trabalho provocando afastamento em relação à família.

Transferências durante a ativa causando o distanciamento da família.

Profissão militar $=$ socialmente valorizada.

Camaradagem militar e solidariedade no ambiente de trabalho como valores importantes de identificação com o trabalho.

Estatuto militar servindo como regulador de condutas pessoais.

Os interesses da instituição se sobrepõem aos interesses pessoais do militar.

A progressão na carreira independe da competência profissional..

Características da vida militar fortalecem o vínculo com a instituição.

Trabalhar com o que gosta $=$ experiência de prazer.

Viver o trabalho com garra, gerando satisfação.

Desejo de fazer o melhor, pelo valor atribuído ao trabalho.

Dificuldades como incentivo para buscar soluções.

Envolvimento com o trabalho como condição de bem-estar.

Exxito no trabalho associado à sensação de não ser substituível.

Atribuições de confiança e responsabilidade dando mais valor ao trabalho feito.

Padrão próprio de competência no trabalho como modelo para os filhos.

Falta de reconhecimento pelo trabalho realizado diminui a autoestima.

Avaliação do que não alcançou na vida inclui frustração com o não feito no trabalho.

Frustração por não corresponder às expectativas leva à busca por compensações diversas.
A vida militar:

impactos e peculiaridades do trabalho
Diferentes matizes

das vivências

laborais regulando

o valor narcísico 
estudo, desempenhar um modelo para os filhos de competência no trabalho e obter êxito e reconhecimento pelas tarefas realizadas configuravam-se como experiências satisfatórias que iam ao encontro dos projetos profissionais. Entretanto, para outros participantes da pesquisa, uma frustração diante do que não foi possível alcançar e a falta de reconhecimento contemplam uma decepção narcísica. As falas seguintes manifestam a forma como o as vivências no trabalho regulam a autoestima:

"Gostaria de ter outro posto, de ser tenente ou capitão. Não sei se é por condição financeira ou status. Vai ver, porque penso que eu poderia ter feito melhor.” (P10, Sargento)

"Eu nunca imaginava ter essa sequência, essa carreira toda. Então, a minha expectativa sempre foi ótima, porque eu vim lá de baixo. Tudo aquilo que eu consegui, para mim foi bastante. Desde o inicio das minhas expectativas, eu alcancei muito mais do que en podia imaginar. Isso sempre foi uma coisa que me deu satisfação, en fiquei realizado, muito satisfeito." (P11, Coronel)

Mediante as singularidades das experiências advindas da atividade militar, estrutura-se a segunda categoria final denominada "Demandas psíquicas frente ao rompimento com a atividade de trabalho" (Tabela 3).

Verificou-se que a passagem para a reserva, compreendida a partir do encerramento dos investimentos psíquicos até então dirigidos ao mundo do trabalho, desperta uma diversidade de sentimentos. A presença de sentimentos ambivalentes, como libertação e crise perante o distanciamento do trabalho em função da aposentadoria, é destacada por Santos (1990). Percebe-se, por meio das falas dos militares entrevistados, que, de fato, a reserva pode compreender ambos os significados:

"É igual se a senhora tem um passarinho na gaiola e soltar, ele vai ficar alegre, vai voar e a senhora nunca mais vai ver. (...) Na reserva, a gente tem mais liberdade para fazer as coisas que quer. Eu me senti melhor assim, me senti passarinho solto.” (P8, Sargento)

"No começo, foi difícil acordar em casa e não ter o que faz̧er. No começo, é um vazio. Eu acredito que o que mais dificulta a adaptação é a falta do que fažer. Porque tu vira um inútil, um cara que não faz nada, que não tem função nenbuma. Se tu ficar em casa, tu murcha. No momento que tu não está ocupado, tu começa com aquelas doenças que são normais nas pessoas que ficam isoladas: depressão, insatisfação, ansiedade." (P6, Suboficial)
A condição de parar de trabalhar, vinculada ao tornar-se inativo e ficar em casa é motivo de preocupação para os participantes deste estudo. Tal percepção encontra-se associada ao que Enriquez (1999) descreve como consequência das representações coletivas do trabalho: não trabalhadores são vistos como parasitas $\mathrm{e}$ inúteis. Observa-se essa conotação da aposentadoria no seguinte discurso:

"Eu tenho 53 anos, você não pode mandar um soldado correr na guerra com um fuzil nas costas aos 53 anos. Mas você poderia tranquilamente colocar ele para trabalhar num computador. A maioria dos meus amigos está com vigor físico, com capacidade intelectual, tudo pronto para produzir, mas estão em casa. Se você for para a reserva e se recolher em casa, você vai virar um "Zé Mané" e socialmente você deixa de existir. Incomoda não fazer nada produtivo. A gente poderia ser melhor aproveitado. Acho que eu poderia produzir mais." (P4)

Para Santos (1990), a resistência em assumir uma condição de aposentado, manifestada por meio da aposentadoria-recusa, representa a proteção contra sentimentos de angústia e vazio, contra a percepção da morte e da velhice. Constata-se a inquietação dos entrevistados frente a temáticas conflituosas decorrentes da aposentadoria. Assuntos como depressão, ansiedade, alcoolismo, isolamento, suicídio e morte foram manifestados, utilizando certa impessoalidade. A opção por essa forma indireta de discurso pode estar associada à compreensão de que, para o sujeito que trabalhou a maior parte da vida, afastar-se do contexto laborativo pode situá-lo em vias de contramão de um projeto social de homem trabalhador e viril (Coutinho et al., 2007). Assim, falar a respeito de conflitos próprios de uma crise em terceira pessoa demonstra a dificuldade na apropriação do sofrimento:

\footnotetext{
"A gente conbece casos ai de colegas que foram obrigados a ir para a reserva por data limite, por compulsória. Três meses depois, o cara morreu. Tem gente que não aceita. Nós tivemos problema de gente que tentou se suicidar. Um caso sério, o cara entrou em parafuso." (P9, Coronel)
}

A percepção de temáticas, como insegurança, sensação de vazio, sentimento de culpa e fantasia sobre ser esquecido após a passagem para a reserva, são amenizadas pela continuidade do exercício das atividades laborais. A volta ao trabalho após a aposentadoria reflete a dificuldade para construir projetos desvinculados da atividade profissional e demonstra 
Tabela 3. Segunda Categoria Final

\begin{tabular}{|c|c|c|}
\hline Categorias iniciais & $\begin{array}{l}\text { Categorias } \\
\text { intermediárias }\end{array}$ & $\begin{array}{l}\text { Segunda categoria } \\
\text { final }\end{array}$ \\
\hline Reserva $=$ momento de desfrutar/satisfação. & \multirow{10}{*}{$\begin{array}{l}\text { Sentimentos frente } \\
\text { à passagem } \\
\text { para a reserva }\end{array}$} & \multirow{30}{*}{$\begin{array}{l}\text { Demandas } \\
\text { psíquicas frente } \\
\text { ao rompimento } \\
\text { com a atividade de } \\
\text { trabalho }\end{array}$} \\
\hline Reserva=liberdade/alívio. & & \\
\hline Reserva $=$ premiação. & & \\
\hline Sensação de "missão cumprida" diante da passagem para a reserva. & & \\
\hline Estar na reserva jovem, gerando sentimento de culpa. & & \\
\hline Passagem para a reserva gerando sentimentos de insegurança. & & \\
\hline Reserva gerando sentimentos de vazio. & & \\
\hline $\begin{array}{l}\text { Passagem para a reserva provocando preocupação sobre a saída do } \\
\text { trabalho para ficar em casa. }\end{array}$ & & \\
\hline Passagem para a reserva despertando a necessidade de se sentir útil. & & \\
\hline Passagem para a reserva despertando preocupação sobre ser esquecido. & & \\
\hline Vínculos fora do ambiente de trabalho facilitando a reserva. & \multirow{6}{*}{$\begin{array}{l}\text { Diversidade de } \\
\text { investimentos } \\
\text { psíquicos como } \\
\text { aspecto facilitador } \\
\text { da passagem para a } \\
\text { reserva }\end{array}$} & \\
\hline Atividade profissional fora do âmbito militar durante a ativa facilitando & & \\
\hline a reserva. & & \\
\hline Boas relações familiares facilitando a passagem para a reserva. & & \\
\hline Continuar trabalhando após a passagem para a reserva. & & \\
\hline Na reserva, o vínculo com a instituição continua. & & \\
\hline Relatos sobre colegas que sofreram de depressão na reserva. & \multirow{6}{*}{$\begin{array}{l}\text { Uso de } \\
\text { impessoalidade } \\
\text { como facilitador } \\
\text { da exposição } \\
\text { de temáticas } \\
\text { conflituosas } \\
\text { associadas à reserva }\end{array}$} & \\
\hline $\begin{array}{l}\text { Constatação de colegas que passaram a fazer uso de bebidas alcoólicas } \\
\text { depois que foram para a reserva. }\end{array}$ & & \\
\hline Percepção sobre colegas que se suicidaram na reserva. & & \\
\hline Associação da passagem para a reserva com a temática da ansiedade. & & \\
\hline Associação da reserva com isolamento. & & \\
\hline Associação da reserva com a morte. & & \\
\hline Reserva representando rompimento repentino com a vida no quartel. & \multirow{8}{*}{$\begin{array}{l}\text { Busca de atribuição } \\
\text { de sentido frente } \\
\text { à passagem para a } \\
\text { reserva }\end{array}$} & \\
\hline Passagem para a reserva provocando alterações no convívio social. & & \\
\hline $\begin{array}{l}\text { Passagem para a reserva encarada como processo natural diminui } \\
\text { sensação de crise. }\end{array}$ & & \\
\hline $\begin{array}{l}\text { Reserva compreendida como uma resistência à qual é necessário se } \\
\text { adaptar. }\end{array}$ & & \\
\hline $\begin{array}{l}\text { Constatação de que também ocorre com os outros diminui a } \\
\text { frustração. }\end{array}$ & & \\
\hline Associação da reserva com “pegar outra etapa” alivia frustrações & & \\
\hline $\begin{array}{l}\text { Possibilidade de racionalizar proporciona aceitação para o que não } \\
\text { pode mudar. }\end{array}$ & & \\
\hline $\begin{array}{l}\text { Preparação/planejamento prévios facilitando a passagem para a } \\
\text { reserva. }\end{array}$ & & \\
\hline $\begin{array}{l}\text { Decisão pela reserva por discordância com os superiores } \\
\text { hierárquicos. }\end{array}$ & \multirow{4}{*}{$\begin{array}{l}\text { Passagem } \\
\text { para a reserva } \\
\text { como forma de } \\
\text { enfrentamento de } \\
\text { conflitos }\end{array}$} & \\
\hline Decisão pela reserva pela falta de reconhecimento. & & \\
\hline $\begin{array}{l}\text { Decisão pela reserva pelo fim da possibilidade de progressão na } \\
\text { carreira. }\end{array}$ & & \\
\hline Decisão pela reserva antes de ser mandado embora pelo sistema. & & \\
\hline
\end{tabular}


o desejo de continuar produtivo e participante do circuito social. Percebe-se, nas verbalizações seguintes, que há uma evitação de um real rompimento com o mundo do trabalho:

"Para mim, foi tranquilo. Eu não sofri com isso. Foi muito corrido, porque, quando eu recebi o convite para trabalhar na aviação civil, foi questão de dias. Enquanto publicava a minha reserva no diário oficial, eu já estava sendo contratado na empresa. Foi uma coisa embolada com a outra." (P9, Coronel)

Os sentidos atribuídos à inatividade apontam a tentativa dos entrevistados de abrandar as frustrações decorrentes de uma crise. No entanto, o estudo realizado por Barisch (2006) parece contrapor a tranquilidade e a naturalidade enunciadas pelos participantes desta pesquisa e dar sustentação à hipótese de negação frente aos conflitos próprios da aposentadoria. Mediante um questionário aplicado a 49 militares da reserva da Aeronáutica, o autor constatou que $54 \%$ das opiniões dos participantes demonstraram ser habitual a ocorrência de dificuldades emocionais (estresse, alcoolismo, depressão e isolamento) após a passagem para a reserva. A associação entre a reserva e problemáticas na saúde física foi indicada por $64 \%$ dos respondentes ao questionário. O índice de $86 \%$ foi resultado da apuração de que a reserva é acompanhada de complicações sociais, como perda de status e de prestígio, acomodação intelectual e exclusão social.

Os militares entrevistados demonstram que a ida para a reserva está associada também às dificuldades relacionadas ao rompimento repentino com a vida no quartel, e não apenas com a rotina de trabalho. Barisch (2006) destaca que essa ruptura se agrava em função das exigências militares de dedicação exclusiva e disponibilidade permanente, o que fortalece o vínculo com a instituição e dificulta o processo de ajustamento social na inatividade. Mesmo na reserva, o militar permanece disponível à instituição, podendo ser (re)convocado a qualquer momento. $\mathrm{O}$ afastamento do serviço ativo acarreta, ainda, o distanciamento das relações interpessoais decorrentes do convívio profissional e da coabitação em vilas militares. Logo, ocasiona-se um abalo nas rotinas e modalidades de sociabilidade construídas a partir do ambiente de trabalho (Barisch, 2006).

No caso dos militares entrevistados, a exigência de trabalho psíquico frente à passagem para a reserva parece configurar-se de forma semelhante ao trabalho do luto. A concepção apresentada por Freud
(1915/1996) em Luto e melancolia considera que, diante da perda de um objeto de grande estima, há a exigência de um trabalho intrapsíquico em direção a um movimento progressivo de desapego. Esse processo envolve o desligamento gradual da libido direcionada ao objeto, de forma que permite o reinvestimento em outros objetos. Assim, o encontro de novos objetos de investimento para a manutenção da atividade libidinal configura-se como uma forma saudável de enfrentar o afastamento da vida laboral. Uma diversidade de investimentos psíquicos é revelada pelos entrevistados como um aspecto facilitador da passagem para a reserva. Tanto no serviço ativo quanto na inatividade, os participantes referem a importância de ter outras atividades e outros vínculos. Percebe-se que há uma tentativa, por parte dos militares, de atenuar a crise psíquica decorrente da passagem para a reserva. Assim, há o reconhecimento de uma vivência acompanhada de dificuldades, ao mesmo tempo em que nota-se uma busca por compensações:

"Como militar, você participa de uma instituição, está trabalhando e está sendo responsável por um setor. De repente você sai fora! É um corte abrupto. Mas não tive nenbum problema. Não tive esse trauma de sair. Não sei o que é depressão. A gente racionaliza, pensa que não adianta, é assim. Não posso mudar isso, vou ter que me adaptar. Os outros estão passando por isso, eu vou passar também. Então, você não vai se frustrar por isso. (...) Sabe o que é que facilita? É ter outras coisas, outras prioridades, outros valores, outras atividades para fazer e não viver só em cima daquilo porque quando acaba, não tem mais nada. O que evita realmente de você ter um baque é ter outros valores e outras coisas para fazer, entende?" (P11, Coronel)

A tentativa de encontrar aspectos que facilitem a passagem para a reserva, bem como o embaraço para falar a respeito do próprio sofrimento, seja mediante o uso da impessoalidade ou da negação, revelam a dificuldade de reconhecer-se na condição de um sujeito em conflito. No entanto, ao longo das entrevistas, surgem os conflitos subjacentes às particularidades da vivência da aposentadoria no contexto militar.

Entre as características do militarismo, destacam-se os princípios de ordem hierárquica e disciplina, configurando-se como crime o desrespeito à hierarquia mediante a concepção de que o militar "jamais deve contrapor-se à Instituição a que pertence e ao próprio Estado, devendo-lhes fidelidade irrestrita" (Barisch, 2006, p. 24). As razões descritas pelos entrevistados 
como motivadoras da decisão pela reserva revelam que esse momento configura-se como uma modalidade de enfrentamento de conflitos vividos durante a vida na ativa, seja pela discordância com superiores hierárquicos, pela falta de reconhecimento ou pela estagnação na carreira. Nessas situações, ir para a reserva constituiu-se como única possibilidade opor-se:

"Tem certos momentos da vida militar que a gente só pode dizer "não senhor". Por quê?? Porque a gente tem razão. Que isso ai foi um dos motivos que me fez pedir a reserva. Eu tinha mais tempo para ficar, mas decidi ir para a reserva porque eu não estava aceitando as ideias que vinham de cima. Para não bater de frente com os de cima, eu resolvi sair." (P1, Sargento)

A passagem para a reserva parece configurar-se como um momento de revelar a discordância ou de contestar um sistema até então inquestionável. $\mathrm{O}$ descontentamento é velado e desvela-se no momento da ruptura, quando não há tantos impedimentos para a emergência dos conflitos. Nota-se a dificuldade para falar dos conflitos inerentes a uma vivência de crise, ao mesmo tempo em que o discurso manifesta uma demanda de escuta. Por meio de recursos que aludem a um certo distanciamento do sujeito em relação às emoções envolvidas na saída do trabalho, ou ainda, no intuito de manter sob controle os efeitos decorrentes de importantes decisões pessoais, os entrevistados permitiram evidenciar a importância da palavra nas diferentes tentativas de atribuir sentido à experiência de aposentadoria. Constatou-se a maneira pela qual um convite para participar de uma entrevista no cenário da pesquisa proporciona uma condição de escuta àquilo que está além da racionalidade, não se restringindo à descrição de processos e padrões previstos e autorizados pela instituição militar. Por meio das falas, que relatavam os processos da ida para a reserva, os participantes revelavam, mesmo sem perceber, a existência de singulares "reservas" humanas a partir da singular experiência frente à aposentadoria. Assim, apresenta-se a terceira categoria final, chamada "O recurso da escuta na pesquisa desvelando a reserva do sujeito" (Tabela 4).

Podem-se aplicar ao contexto da pesquisa as reflexões que Macedo e Carrasco (2005) fazem sobre a entrevista clínica. As autoras compreendem que uma conversa em um contexto de entrevista "cria condições para que, mediante a criação de um espaço de diálogo, se tenha acesso à subjetividade em forma de discurso" (p. 22). O espaço da entrevista com os participantes possibilitou uma aproximação às significações particulares desses sujeitos acerca da mescla entre aspectos da vida pessoal e da vida laboral. O relato sobre o cotidiano do trabalho revelou o modo de ser dos entrevistados.

Sabe-se que, por trás da palavra, há um sujeito que, ao proferi-la, diz mais do que inicialmente se propunha. Por meio de associações, a narrativa dos entrevistados sobre acontecimentos vividos no âmbito da vida laborativa desperta a necessidade de compartilhar experiências de conflito no trabalho, frustrações na carreira e descontentamento com a instituição. Assim, os participantes trazem em suas falas queixas quanto a expectativas pessoais frustradas no mundo do trabalho:

"Eu já estava com 32 anos e meio de serviço e eu só vi tirarem meus direitos. Então, eu podia continuar aí mais dois, três, quatro, cinco anos; mas eu preferi sair, porque daqui a pouco vão me tirar mais coisas." (P12, Capitão)

Observa-se que, a partir do relato de vivências conflituosas no contexto do trabalho, a complexidade de uma história singular se impõe. Rocha (2008), ao realizar uma reflexão a respeito da experiência psicanalítica, destaca que esta contempla um modelo para as experiências humanas em geral, nas quais a palavra torna possível a criação de novos significados para antigas experiências. Percebeu-se, na fala dos participantes sobre o trabalho e a aposentadoria, um pedido de escuta sobre questionamentos situados no espaço privado:

"A senhora pode até cortar isso aqui, mas vai ser um despejo meu. Depois a senhora faz os cortes, aproveita o que ficou bom. É bom a gente, às vezes, conversar. Porque o meu pai dava em mim com cabo de vassoura e relho, eu vou pegar os meus e vou fazer a mesma coisa? Não. Eu vou tentar conversar. Bah, minha pele ardeu. E nunca precisei bater nos filhos, e até hoje são todos amigos meus." (P8, Sargento)

A entrevista parece estabelecer um espaço de desabafo na tentativa de ter acesso a algum tipo de significação para vivências angustiantes. Por meio da expressão da palavra, percebe-se a insistência do conflito em ser escutado e elaborado. Assim, os discursos produzidos e a escuta oferecida nas entrevistas inauguraram, para alguns participantes, um espaço possível de elaboração psíquica de situações conflitivas, com o intuito de conter a angústia e dar sentido a uma experiência.

As ideias de outros autores estão harmonizadas com a caracterização que Graeff (2002) faz sobre a 
Tabela 4. Terceira Categoria Final

\begin{tabular}{|c|c|c|}
\hline Categorias iniciais & $\begin{array}{l}\text { Categorias } \\
\text { intermediárias }\end{array}$ & $\begin{array}{l}\text { Terceira categoria } \\
\text { final }\end{array}$ \\
\hline $\begin{array}{l}\text { Referências ao modo de ser na vida, ao relatar atividades do } \\
\text { trabalho. }\end{array}$ & \multirow{8}{*}{$\begin{array}{l}\text { Fronteiras invisíveis } \\
\text { entre vida pessoal e } \\
\text { vida militar }\end{array}$} & \multirow{16}{*}{$\begin{array}{l}\text { O recurso de } \\
\text { escuta na pesquisa } \\
\text { desvelando a } \\
\text { reserva do sujeito }\end{array}$} \\
\hline $\begin{array}{l}\text { Necessidade de compartilhar conflitos vividos durante o trabalho na } \\
\text { ativa. }\end{array}$ & & \\
\hline Reflexões pessoais sobre frustrações da carreira. & & \\
\hline Desabafo sobre o descontentamento com a instituição. & & \\
\hline Apreensão com dificuldades pessoais/ familiares. & & \\
\hline Angústia frente a dificuldades na relação conjugal. & & \\
\hline Questionamentos acerca da criação dos filhos. & & \\
\hline Inquietação com a finitude da vida. & & \\
\hline Dificuldade em ver os outros fazendo o seu trabalho. & \multirow{8}{*}{$\begin{array}{l}\text { Tons do devir: } \\
\text { a reserva } \\
\text { possibilitando } \\
\text { o processo de } \\
\text { historização e } \\
\text { ressignificação da } \\
\text { história pessoal }\end{array}$} & \\
\hline $\begin{array}{l}\text { Desejo/necessidade de preservar a identidade militar após a } \\
\text { passagem para a reserva. }\end{array}$ & & \\
\hline Reserva causando alteração nos papéis sociais e privados. & & \\
\hline Passagem para a reserva causando sentimento de apreensão e & & \\
\hline preocupação nas esposas. & & \\
\hline $\begin{array}{l}\text { Passagem para a reserva possibilitando um maior envolvimento com a } \\
\text { família. }\end{array}$ & & \\
\hline Surge a necessidade de aproveitar o tempo de vida. & & \\
\hline $\begin{array}{l}\text { A forma como a pessoa encara a passagem para a reserva depende da } \\
\text { forma como ela encarou a vida de trabalho. }\end{array}$ & & \\
\hline
\end{tabular}

aposentadoria como uma perda ou como um recomeço. Para Santos (1990), a experiência de perda se reflete no comprometimento dos pontos de referência identificatórios propiciados pela identidade profissional. Segundo Lear (2007), o deixar de ter coisas para fazer implica um deixar de ter coisas para ser. Assim, o término da atividade de trabalho questiona a identidade do sujeito (Carlos et al., 1999; Costa \& Soares, 2009; Santos, 1990). A partir do discurso do entrevistado, observa-se a dificuldade em romper com a identidade militar na reserva:

"Quando estou na ativa, tenho uma farda, e em qualquer lugar que passar fardado as pessoas estão vendo um suboficial, um militar. A partir do momento que tiro ela, passo a ser mais um. Ninguém sabe quem sou na rua. Se perde uma parte, porque tu passou 30 anos sendo visto de uma maneira. De repente tira a farda, ninguém mais te vê como militar." (P5, Suboficial)
Diante do questionamento identificatório advindo do afastamento da vida laborativa, Santos (1990) destaca que, ao deixar de exercer a atividade profissional, o sujeito "terá que refazer sua identidade, interiorizar novos papéis, procurar novos objetivos para sua vida. No momento em que é obrigado a se desfazer do seu papel profissional, ele deverá dar início a um processo de reestruturação de sua identidade" (p. 13). Nesse sentido, cabe retornar à compreensão de Graeff (2002) acerca da aposentadoria como um tempo de recomeço. Para o autor, recomeçar após a aposentadoria significa possibilitar um espaço para "novas práticas que tomem o lugar das atividades anteriores, ocupando um tempo que é sinônimo de ausência" (p. 29).

O período pós-aposentadoria como um recomeço também é apontado por Costa e Soares (2009), ao destacarem a necessidade de "resgatar outras atividades, as quais podem, inclusive, propiciar mais prazer do que as anteriores, estabelecer novos laços 
afetivos, descobrir ou redescobrir desejos, enfim, ter novos projetos de futuro" (p. 103). A passagem para a reserva configura-se, portanto, como um momento de reinvenção narcísica. Para Santos (1990), o mundo familiar configura-se como um meio privilegiado para as novas identificações, em função da acentuação de novos papéis no ambiente doméstico. Nas declarações dos entrevistados, percebem-se as modificações identificatórias decorrentes da alteração de papéis propiciada pela vida em família:

"O cara aposentado muda de nome. Vira "já que": "Iá que tu não está fazendo nada, vai ao supermercado"; "Ah, pai! Já que tu vai ficar em casa, vai lá e paga uma conta para mim, dai eu não preciso sair do serviço". "Já que tu está em casa, então me pega no colégio". Esse é o "já que". Quando o cara vai para a reserva, muda o nome, vira "já que”." (P1, Sargento)

"Minha mãe teve um $A V C$, ai deu correria e seguidamente ela tinha que estar indo para o hospital. (...) Então, nesse ponto, foi interessante eu estar ali." (P13, Sargento)

Para os participantes, o desinvestimento de um modelo identificatório alicerçado no trabalho encontra, na aposentadoria, o espaço familiar como estruturante de novos investimentos ao possibilitar o resgate de laços afetivos e da autoestima. Hornstein (2008) aponta a importância dos vínculos atuais na (re)significação da história do sujeito. O conceito psicanalítico de a posteriori indica o processo psíquico que permite que as experiências não acomodadas em um contexto de significados possam ser remodeladas em função de novas vivências e dotadas de um novo sentido. A vivência de um acontecimento recente permite uma nova significação daquilo que não pode ser integrado aos processos psíquicos de simbolização num tempo anterior. Hornstein (2008) destaca o quanto o processo de historização simbolizante, por meio da lembrança partilhada e transmitida, bem como da palavra dita e escutada, configura-se como uma experiência singular. Assim, viver a reserva e falar sobre ela expressam a singularidade e a complexidade dos processos psíquicos envolvidos nesse decurso.

O desenvolvimento e a preservação da capacidade psíquica para buscar novas e criativas formas de conviver com as manifestações conflitivas constitui-se, segundo Lear (2007), como resultado de um trabalho elaborativo. Para o autor, a elaboração configura-se como um processo psíquico que permite a (re)orientação do ser humano em direção ao progresso. Assim, a fala dos entrevistados denuncia a existência de questionamentos e reflexões que conduzem a projetos de recomeço mediante a constatação de que ainda há tempo para viver:

"Esse ano eu completo 50 anos de vida. E a média de vida do brasileiro é 76 anos. Na minha ideia, tenho mais 26 anos de vida para viver. Então, desse pouco de vida que eu tenho ainda, eu tenho que aproveitar o máximo. O que que eu vou aproveitar? Eu quero viver do lado da minha esposa, viver com os meus filhos, quero ver meus filhos bem criados." (P1, Sargento)

Percebe-se, portanto, que a integração do passado e a manutenção de projetos de futuro configuram-se numa tentativa de dar sentido à própria vida. Segundo Hornstein (2008), a ausência de projetos é uma das causas de grandes vivências de crise. Pode-se apreender, a partir das entrevistas, a importância da palavra em sua função de mediação. Costa (1998) define que mediar significar criar uma ligação entre o passado (não mais) e o futuro (não ainda). A palavra, segundo o autor, possibilita um novo começo por meio da apropriação do passado e da legitimação do futuro. Nesse contexto, a palavra põe em cena uma história que deseja ser escutada.

\section{Considerações Finais}

O processo de aposentadoria é compreendido a partir de uma diversidade de ênfases teóricas na área das ciências humanas. Percebe-se, uma carência de estudos que utilizem a Psicanálise como ferramenta teórica de discussão das relações estabelecidas entre o homem, o contexto laboral e a decorrente aposentadoria. A compreensão psicanalítica dessas inter-relações na especificidade do contexto militar desvela as matizes singulares de uma experiência em que a passagem da vida ativa para a reserva realiza-se por meio de uma travessia psíquica que põe em cheque o valor do si mesmo.

A análise dos dados permitiu identificar que a passagem para a reserva não se encontra, necessariamente, atrelada ao processo de envelhecimento, já que os militares aposentam-se cedo em comparação com outras classes trabalhistas. Logo, esses militares aposentados se encontram com a capacidade produtiva plenamente preservada, permanecendo, muitas vezes, no serviço ativo por mais tempo do que o necessário.

A utilização de mecanismos psíquicos para afastar de si mesmo a percepção da aposentadoria como uma vivência de crise foi revelada pelos participantes. 
A tentativa dos participantes de silenciar o impacto do rompimento de um forte vínculo com a vida militar permite cogitar a precariedade de trabalho psíquico elaborativo diante da ruptura com uma condição laboral que, por vezes, constituiu a totalidade de investimentos pulsionais desses sujeitos. Talvez, justamente nessa exclusão (ou negação) da presença das dores e questionamentos provocados pela aposentadoria, resida uma importante fonte de sofrimento psíquico.

Uma vez sendo a palavra um recurso fundamental no processo de elaboração psíquica, a ausência de condições de nomeação de aspectos ligados à vivência de ruptura com a vida laboral pode constituir uma fonte de mal-estar emocional para o sujeito. A forma como esse processo é conduzido pelos militares denota a presença de motivações localizadas para além da racionalidade, cujas manifestações foram favorecidas na ocasião da entrevista mediante o constante estímulo à fala dos participantes e o cuidado às condições de escuta. Dentro de um contexto com preceitos tão rígidos, a abertura de um espaço de escuta e a experiência de falar sobre o trabalho e a reserva promoveram um movimento de (re)significação. Resgatar o valor de uma história profissional e das conquistas e/ou dificuldades que nela se presentificaram contribui para a possibilidade de encerrar satisfatoriamente um ciclo de investimentos.

Ainda que, referentes a um contexto específico, as falas dos entrevistados neste estudo encontraram ressonância nas pesquisas acerca da aposentadoria no âmbito civil. No entanto, os resultados e a discussão realizados neste artigo não esgotam novas possibilidades de compreensão sobre as vivências decorrentes da relação homem/trabalho no contexto militar, pois o trabalho com os dados coletados e as leituras, que sustentaram a exploração do tema, permite reafirmar a complexidade desse fenômeno. Sugere-se, portanto, a necessidade de novos estudos que objetivem a criação de ações preventivas que promovam a capacidade reflexiva ao militar que está prestes a vivenciar a travessia para a reserva.

\section{Referências}

Bardin, L. (1991). Análise de conteúdo. Lisboa: Edições 70.

Barisch, E. J. A. (2006). Preparaşão para a reserva: necessidade estratégica para a Aeronáutica (Dissertação de mestrado não publicada). Universidade da Força Aérea, Rio de Janeiro.

Bodgan, R., \& Biklen, S. (1994). Investigação qualitativa em educação: uma introdução à teoria e aos métodos. Porto: Porto Editora.
Carlos, S. A., Jacques, M. G. C., Larratea, S. V., \& Heredia, O. C. (1999). Identidade, aposentadoria e terceira idade. Estudos interdisciplinares sobre o envelhecimento, 1, 77-88.

Costa, A. B., \& Soares, D. H. P. (2009). Orientação psicológica para a aposentadoria. Revista Psicologia: Organizações e Trabalho, 9(2), 97-108.

Costa, J. F. (1998 ). Não mais, não ainda: a palavra na democracia e na psicanálise. Revista USP, 37, 108-119.

Coutinho, M. C., Krawulski, E., \& Soares, D. H. P. (2007). Identidade e trabalho na contemporaneidade: repensando articulações possíveis. Psicologia ed Sociedade, 19, edição especial, 29-37.

Enriquez, E. (1999). Perda do trabalho, perda da identidade. In M. R. Nabuco e A. C. Neto (Orgs.), Relaçôes de trabalho contemporâneas (pp. 69-83). Belo Horizonte: Instituto de Relações do Trabalho (IRT) da PUC Minas.

Freud, S. (1996). Três ensaios sobre a teoria da sexualidade. In Freud, S (Ed.), Edição Standard Brasileira das Obras Psicológicas Completas de Sigmund Freud (Vol. 7, pp. 119-229, J. Strachey, trad.). Rio de Janeiro: Imago. (Original publicado em 1905).

Freud, S. (1996). Luto e melancolia. In Freud, S (Ed.), Edição Standard Brasileira das Obras Psicológicas Completas de Sigmund Freud (Vol. 14, pp. 243-263, J. Strachey, trad.). Rio de Janeiro: Imago. (Original publicado em 1915).

Freud, S. (1996). A negativa. In Freud, S (Ed.), Edição Standard Brasileira das Obras Psicológicas Completas de Sigmund Freud (Vol. 19, pp. 261-269, J. Strachey, trad.). Rio de Janeiro: Imago. (Original publicado em 1925).

Freud, S. (1996). O mal-estar na civilização. In Freud, S (Ed.), Edição Standard Brasileira das Obras Psicológicas Completas de Sigmund Freud (Vol. 21, pp. 65-148, J. Strachey, trad.). Rio de Janeiro: Imago. (Original publicado em 1930).

Graeff, L. (2002). Representações sociais da aposentadoria. Textos sobre envelhecimento, 4(7), 19-34.

Hornstein, L. (2008). As depressões: afetos e bumores do viver. São Paulo: Via Lettera.

Lear, J. (2007). Elaborar o fim de uma civilização. Revista Brasileira de Psicanálise, 41(1), 137-153. 
Macedo, M. M. K., \& Carrasco, L. K. (2005). A entrevista clínica: um espaço de intersubjetividade. In M. Macedo \& L. Carrasco (Orgs.), (Con)textos de entrevista: olhares diversos sobre a interação bumana (pp. 19-32). São Paulo: Casa do Psicólogo.

Moraes, R. (1999). Análise de conteúdo. Educação, 37(22), 7-32, Porto Alegre: PUCRS.

Morin, E., Tonelli, M. J., \& Pliopas, A. L. V. (2007). O trabalho e seus sentidos. Psicologia \& Sociedade, 19, edição especial, 47-56.
Rocha, Z. (2008). A experiência psicanalítica: seus desafios e vicissitudes, hoje e amanhã. Ágora, 11(1), 101-116.

Santos, M. F. S. (1990). Identidade e aposentadoria. São Paulo: EPU.

Recebido em: 10/02/2014

Primeira reformulação em: 11/12/2014

Segunda reformulação em: 29/01/2015

Aprovado em: 09/02/2015

Nota das autoras:

Este trabalho é parte integrante de uma pesquisa de mestrado realizada com o apoio financeiro da CAPES.

Sobre as autoras:

Paula Kegler é psicóloga da Força Aérea Brasileira (FAB), docente do curso de Psicologia das Faculdades Integradas de Taquara (FACCAT), mestre em Psicologia Clínica, doutoranda em Psicologia pelo Programa de Pós-Graduação em Psicologia da Pontifícia Universidade Católica do Rio Grande do Sul (PUCRS) e integrante do grupo de pesquisa Fundamentos e intervenções em psicanálise.

Mônica Medeiros Kother Macedo é psicanalista, doutora em Psicologia, professora titular da graduação e do programa de pós-graduação da Faculdade de Psicologia da Pontifícia Universidade Católica do Rio Grande do Sul (PUCRS), coordenadora do grupo de pesquisa Fundamentos e intervenções em psicanálise e membro do grupo de trabalho Psicanálise, subjetivação e cultura contemporânea da Associação Nacional de Pós-Graduação em Psicologia (ANPEPP).

\section{Contato com as autoras:}

Av. Ipiranga, no 6681. Prédio 11 - $9^{\circ}$ andar - sala 926.

Porto Alegre - RS

CEP: 90619-900

E-mail: kegler.paula@gmail.com 